\title{
A Correlational Study of Reactive Thrombocytosis and Iron Deficiency Anemia
}

\author{
Dr. S. Muthu Ranjani ${ }^{1 *}$, Dr. Gayathri Devi $\mathrm{T}^{2}$, Dr. Hemalatha Ganapathy ${ }^{3}$ \\ Post graduate in pathology ${ }^{1}$, Assistant professor ${ }^{2}$, Professor and Head of the department ${ }^{3}$, Sree Balaji Medical College and Hospital, Chennai, Tamil \\ Nadu, India
}

\author{
DOI: $10.36348 /$ sjmps.2020.v06i11.001 \\ | Received: 12.10.2020 | Accepted: 29.10.2020 | Published: 05.11.2020 \\ *Corresponding author: Dr. S. Muthu Ranjani
}

\section{Abstract}

Aim: To study the correlation of varying degrees of iron deficiency anemia with reactive thrombocytosis. Introduction: Iron deficiency anemia is a very common entity in women belonging to reproductive age group of 15-49 years. Iron deficiency anemia is also a causative factor for reactive thrombocytosis in most cases. The relationship of thrombocytosis in iron deficiency anemia is not yet understood properly. This study was undertaken to correlate the various degrees of thrombocytosis in association with various degrees of anemia. Materials and methods: A total number of 500 female patients belonging to the reproductive age group of 15-49 years, attending the out-patient and in- patient departments, who were identified to have iron deficiency anemia and thrombocytosis which was confirmed with relevant hematological studies including peripheral smear studies done in Sree Balaji Medical College and Hospital, Chennai were included in the study during the period of November 2018 to May 2019. Results: The current study helps in correlation and evaluation of varying degrees of iron deficiency anemia and reactive thromocytosis, which can be used to determine the treatment approach.

Keywords: Thrombocytosis, Iron deficiency anemia, Reproductive women.

Copyright ( ) 2020 The Author(s): This is an open-access article distributed under the terms of the Creative Commons Attribution 4.0 International License (CC BY-NC 4.0) which permits unrestricted use, distribution, and reproduction in any medium for non-commercial use provided the original author and source are credited.

\section{INTRODUCTION}

Iron deficiency anemia is one of the most common hematological disorders observed in females of reproductive age group (15-49 years)[1]. The degree of anemia can be mild, moderate and severe. The treatment modalities for each degree of anemia vary accordingly.

Thrombocytosis can be observing in various hematological disorders, one among them being Iron deficiency anemia. An increase in platelet count in Iron deficiency anemia can be caused by reactive mechanisms which seem to be unclear. IL-6, TNF- $\alpha$ and thrombopoietin are certain thrombopoietic growth factors which have been implicated as a reason of reactive thrombocytosis.

Few studies show elevated IL-6 levels in reactive thrombocytosis [2]. The degree and etiology of thrombocytosis serves as an important factor in deciding the mode of treatment, follow-up and also in preventing further complications such as any thrombotic events. Severe iron deficiency anemia with marked thrombocytosis can also lead to complications like retinal vein occlusion [3]. This study was undertaken to study the correlation of various degrees of iron deficiency anemia with various degrees of thrombocytosis.

\section{Materials and Methods Inclusion criteria}

Female patients belonging to reproductive age group of 15-49 years, who were evaluated for anemia by various hematological tests and were identified to have iron deficiency anemia with thrombocytosis were selected.

\section{Exclusion criteria}

Female patients presenting with anemia other than Iron deficiency anemia and of other etiological factors such as bleeding disorders, auto-immune conditions, sickle cell anemia and thalassemia, were excluded from the study.

\section{SAMPLING MeTHOD}


Out of 4862 patients who were evaluated for anemia with relevant hematological tests and found to have iron deficiency anemia subjected to low serum ferritin levels, a convenient sample of 500 female patients of reproductive age group (15-49 years), with thrombocytosis, identified with peripheral smear studies were selected for this current study.

\section{Statistical Analysis}

The obtained data was tabulated and analysed using statistical package for social services (version 20).

\section{Anemia was graded as mild, moderate and severe on} hemoglobin concentration [4]:
a) Mild ( $\mathrm{Hb} 10-11 \mathrm{gm} / \mathrm{dl}$ )
b) Moderate ( $\mathrm{Hb} 7-9.9 \mathrm{gm} / \mathrm{dl}$ )
c) Severe $(\mathrm{Hb}<7 \mathrm{gm} / \mathrm{dl})$

Thrombocytosis was also graded as:
a) Mild ( 5-7 lakhs/cu.mm)
b) Moderate ( 7-9 lakhs/cu.mm)
c) Severe ( $>9$ lakhs/cu.mm)

\section{RESULTS}

In the current study, majority of the $48 \%$ ( $n=$ 240) cases had moderate anemia between $7-9.9 \mathrm{gm} / \mathrm{dl}$, $28 \%(\mathrm{n}=140)$ cases had severe anemia of $<7 \mathrm{gm} / \mathrm{dl}$ and $24 \%(n=120)$ cases had mild anemia between $\mathrm{Hb} 10$ $11 \mathrm{gm} / \mathrm{dl}$ (Table 1).

Table-1: Showing distribution of cases in relation to various grades of anemia

\begin{tabular}{|l|l|l|}
\hline GRADES OF ANEMIA & NO. OF PATIENTS & PERCENTAGE \\
\hline MILD ( Hb 10-11gm/dl ) & 120 & 24 \\
\hline MODERATE ( Hb 7-9.9gm/dl ) & 240 & 48 \\
\hline SEVERE ( Hb 7-9.9gm/dl ) & 140 & 28 \\
\hline TOTAL (n=500) & 500 & 100 \\
\hline
\end{tabular}

In the current study, majority $59 \%(\mathrm{n}=295)$ cases had mild thrmbocytosis (5-7 lakhs/cu.mm), 31\% $(n=155)$ cases had moderate throbocytosis (7-9 lakhs/cu.mm $)$ and $10 \%(\mathrm{n}=50)$ cases had severe thrombocystosis Severe (>9 lakhs/cu.mm) (Table 2).

Table-2: Showing distribution of cases in relation to grades of thrombocytosis

\begin{tabular}{|l|l|l|}
\hline GRADES OF THROMBOCYTOSIS & NO. OF PATIENTS & PERCENTAGE \\
\hline MILD ( 5-7 lakhs/cu.mm) & 295 & $59 \%$ \\
\hline MOERATE ( 7-9 lakhs/cu.mm) & 155 & $31 \%$ \\
\hline SEVERE ( >9 lakhs/cu.mm) & 50 & $10 \%$ \\
\hline TOTAL ( $\mathrm{n}=$ 500) & 500 & 100 \\
\hline
\end{tabular}

The current study shows that most of the cases $485(\mathrm{n}=240)$ had moderate anemia between with $\mathrm{Hb} 7-$ $9.9 \mathrm{gm} / \mathrm{dl}$, of which $66.66(\mathrm{n}=160)$ cases had mild thrombocytosis, $22.91 \% \quad(n=55)$ had moderate thrombocytosis and $10.41 \% \quad(\mathrm{n}=25)$ had severe thrombocytosis. There was statistically significant and positive correlation between hemoglobin percentage and platelet count. (p value $<0.01$, Fig) (Table 3).

Table-3: Showing status of grades of anemia in relation to grades of thrombocyosis.

\begin{tabular}{|l|l|l|l|}
\hline ANEMIA & $\begin{array}{l}\text { MILD } \\
\text { THROMBOCYTOSIS } \\
\text { (5-7 lakhs/cu.mm) }\end{array}$ & $\begin{array}{l}\text { MODERATE } \\
\text { THROMBOCYTOSIS } \\
\text { (7-9 lakhs/cu.mm) }\end{array}$ & $\begin{array}{l}\text { SEVERE } \\
\text { THROMBOCYTOSIS } \\
\text { ( >9 lakhs/cu.mm) }\end{array}$ \\
\hline $\begin{array}{l}\text { MILD (Hb 10-11gm/dl) } \\
\text { n=120 }\end{array}$ & $70(58.33 \%)$ & $45(37.50 \%)$ & $5(41.66 \%)$ \\
\hline $\begin{array}{l}\text { MODERATE (Hb 7-9.9gm/dl) } \\
\text { n= 240 }\end{array}$ & $160(66.66 \%)$ & $55(22.91 \%)$ & $25(10.41 \%)$ \\
\hline $\begin{array}{l}\text { SEVERE (Hb 7-9.9gm/dl) } \\
\text { n= 140 }\end{array}$ & $65(46.42 \%)$ & $55(39.28 \%)$ & $20(14.28 \%)$ \\
\hline TOTAL (n=500) & $295(59 \%)$ & $155(31 \%)$ & $50(10 \%)$ \\
\hline
\end{tabular}

Bar diagram 1- Representation of prevalence of varying degrees of anemia and its percentage of distribution in the current study population of 500 cases. 


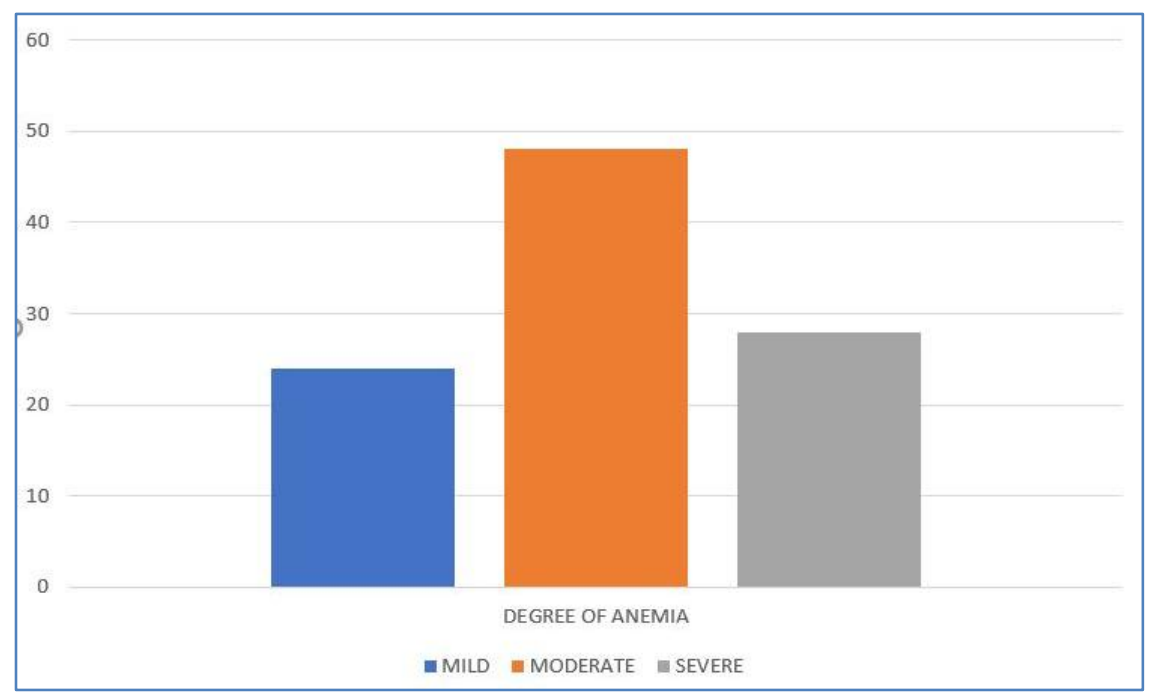

Bar diagram 2- Representation of prevalence of varying degrees of thrombocytosis and its percentage of distribution in the current study population of 500 cases

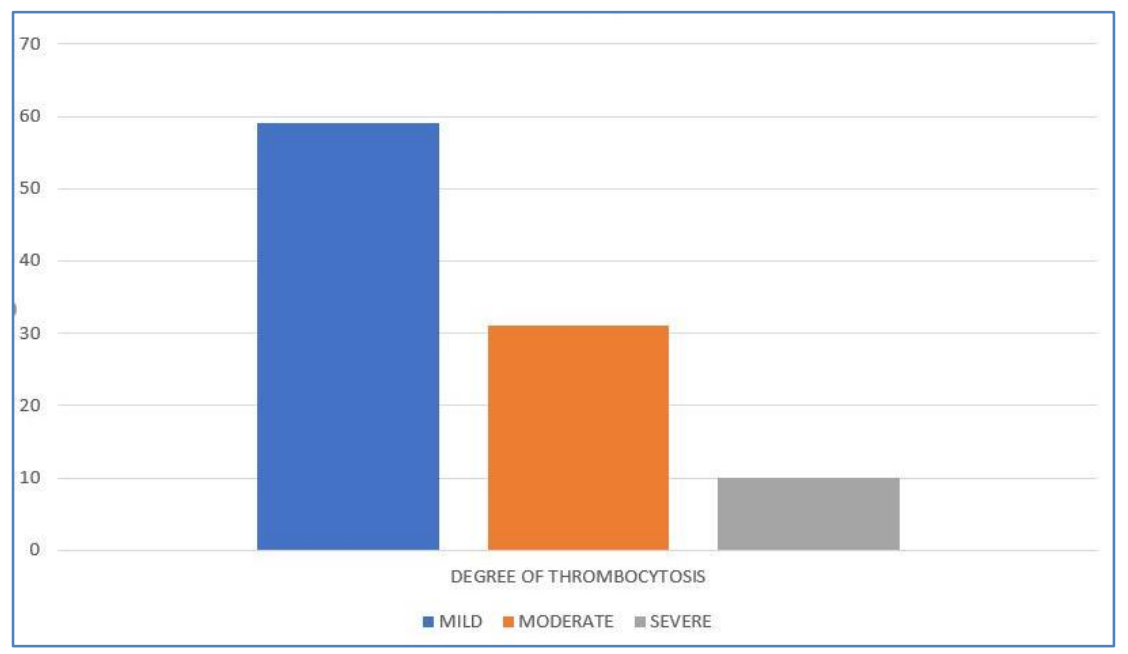

\section{DISCUSSION}

Iron deficiency anemia is one of the most common hematological disorders due to improper balance of iron intake, iron storage and iron loss in the body. It is one of the common nutritional ailments encountered especially in developing countries like India. The human body absorbs only $15-10 \%$ of dietary iron consumed which is also an important consideration in treating iron deficiency anemia patients.

The iron balance in the human body is maintained by a variety of factors including the recently identified peptide- Hepcidin [5]. Free iron on binding with ferritin or hemosiderin is the usual form of stored iron in the body. In iron deficiency anemia, the synthesis of globin is decreased and hence the red blood cell has decreased hemoglobin resulting in microcytic hypochromic anemia. Initially, this loss would be compensated by the iron stores in the body so as to maintain normal hemoglobin. When these stored forms of iron also also start to get depleted, the serum iron and transferrin saturation levels get lowered, yet without actual clinical manifestation of anemia. When there occurs complete depletion of iron reserves in the body, it results in lowered serum iron, serum ferritin and transferrin saturation levels [6].

Iron deficiency anemia, adversely affects the cognitive performance, immune status, performance of daily physical activities and may even lead to death in extreme cases.

Iron deficiency anemia, though affecting all age groups of the world's population, poses a major threat by being risk factor in anemia affecting the women especially belonging to the reproductive age group of 15-49 years. Epidemiological studies state that nearly $50 \%$ of pregnant women in the total population of the world are affected by anemia [7]. Studies also show that adolescent women do not consume enough iron supplements to compensate the menstrual loss. During pregnancy, especially in the second and third 
trimesters, the demands exceed the body's capacity to extract sufficient iron from the diet even if the bioavailabiity is high.

Reactive thrombocytosis is an increase in platelet count ( $>4.5$ lakhs/cu.mm) due to an underlying secondary cause such as iron deficiency anemia, chronic inflammation, chronic infection, surgical causes such as splenectomy and malignancies. There are not much informations regarding the mechanisms causing reactive thrombocytosis in iron deficiency anemia.

IL-6. TNF- $\alpha$ an thrombopoietin are certain growth factors which are expected to be few causes of reactive thrombocytosis. Erythropoietin may stimulate the platelet production indirectly by stimulating MEG proliferation along with other megakaryopoietic cytokines [8].

Thrombocytosis in initial levels may not be threatening, but occasionally it can lead thrombotic complications also. When blood viscosity gets increased as in case of pregnancy, there are higher chances of thromboembolic events to occur which adds up to the reactive thrombosis in pregnant women with iron deficiency anemia [9].

Few studies show inverse relationship between platelet count and iron saturation. It also shows that in iron deficiency anemia, megakaryopoiesis was stimulated [10]. Studies indicate that due to increase in the rate of influx of precursor cells, decreased maturation of magakaryocytes and inhibition of erythropoiesis due to compensatory mechanisms, thrombocytosis may occur in iron deficiency anemia.

Clinical features of iron deficiency anemia include complete blood count, which exhibit low red cell indices, peripheral smear showing microcytic hypochromic anemia and anisopoikiocytosis. In iron deficiency anemia red cell distribution width is increased which differentiates it from thalassemia trait where RDW is normal. Anemic patients have considerably low levels of hemoglobin. Patients with iron deficiency anemia have very low levels of ferritin and transferrin saturation, which form important biochemical parameters to be considered in evaluating and diagnosing a case of iron deficiency anemia [11]. The bone marrow picture reveals moderate levels of erythroid hyperplasia and normally appearing normoblasts with scant cytoplasm and irregular cell borders [12].

The current study was undertaken to evaluate the correlation of various grades of anemia with varying grades of thrombocytosis in 500 women belonging to reproductive age group and the results show predominantly $48 \%(\mathrm{n}=240)$ of the study population have moderate anemia, $28 \% \quad(n=140)$ have severe anemia and 24\% ( $n=120)$ have mild anemia. Among $48 \%$ of the study population who have moderate anemia, 66.66\% $(\mathrm{n}=160)$ have mild thrombocytosis, $22.91 \% \quad(n=55)$ have moderate thrombocytosis and $10.41 \%(\mathrm{n}=25)$ have severe thrombocytosis. Among $28 \%$ of the study population who have severe anemia, $46.42 \% \quad(\mathrm{n}=65)$ have mild thrombocytosis, $39.28 \%$ $(\mathrm{n}=55)$ have moderate thrombocytosis and $14.28 \%$ $(n=20)$ have severe thrombocytosis. Among 24\% of the study population who have mild anemia, $58.33 \%$ $(n=70)$ have mild thrombocytosis, $37.50 \%(n=45)$ have moderate thrombocytosis and $41.66 \% \quad(n=5)$ have severe thrombocytosis. Hence, the results of this study suggest that majority of the reproductive women suffer from moderate anemia associated with mild reactive thrombocytosis.

\section{CONCLUSION}

To conclude, the current study shows that majority of the women belonging to reproductive age group have a moderate degree of iron deficiency anemia with associated mild reactive thrombocytosis. Though there has not been many studies to identify the causative factors for reactive thrombocytosis in iron deficiency anemia, the prevalence of reactive thrombocytosis in iron deficiency anemia has been proved by various studies. The modality of treating the iron deficiency anemia patients vary according to the degree of anemia. The risk associated with thrombotic events due to reactive thrombocytosis also varies according to the severity of thrombocytosis. Hence, this study can help in understanding that the prevalence of moderate anemia with mild thrombocytosis is more common which helps in assigning proper treatment approach to the majority of the study population.

\section{REFERENCES}

1. WHO. (2015). The global prevalence of anaemia in 2011. Geneva: World Health Organization.

2. Tefferi, A., Ho, T. C., Ahmann, G. J., Katzmann, J. A., \& Greipp, P. R. (1994). Plasma interleukin-6 and $\mathrm{C}$-reactive protein levels in reactive versus clonal thrombocytosis. The American journal of medicine, 97(4), 374-378.

3. Nagai, T., Komatsu, N., Sakata, Y., MIURA, Y., \& OZAWA, K. (2005). Iron deficiency anemia with marked thrombocytosis complicated by central retinal vein occlusion. Internal medicine, 44(10), 1090-1092.

4. Tania, O., Alka, B. (2016). To Study Hematological Abnormalities of Platelet Count in Children With Iron Deficiency Anemia In India. Intl.J of scientific research, 5(4): 90-95.

5. Kohgo, Y., Ikuta, K., Ohtake, T., Torimoto, Y., \& Kato, J. (2008). Body iron metabolism and pathophysiology of iron overload. International journal of hematology, 88(1), 7-15.

6. Red blood cell and bleeding disorders. (2010). In: Kumar V, Abbas AK, Fausto N, Aster JC eds. 
Robbins and Cotran Pathologic Basis of Disease.8th ed. New Delhi: Elsevier, 639-76.

7. McLean, E., Cogswell, M., Egli, I., Wojdyla, D., De Benoist, B. (2009). Worldwide prevalence of anaemia, WHO vitamin and mineral nutrition information system, 1993-2005. Public health nutrition, 12(4):444-54.

8. Evstatiev, R., Bukaty, A., Jimenez, K., KulniggDabsch, S., Surman, L., Schmid, W., ... \& Khare, V. (2014). Iron deficiency alters megakaryopoiesis and platelet phenotype independent of thrombopoietin. American journal of hematology, 89(5), 524-529.

9. Toprak, S. K., Tek, İ., Karakuş, S., Gök, N., \& Kurşun, N. (2012). Does reactive thrombocytosis observed in iron deficiency anemia affect plasma viscosity?. Turkish Journal of Hematology, 29(3), 248.

10. Kadikoylu, G., Yavasoglu, I., Bolaman, Z., \& Senturk, T. (2006). Platelet parameters in women with iron deficiency anemia. Journal of the national medical association,98(3), 398. Kadikoylu, G., Yavasoglu, I., Bolaman, Z., \& Senturk, T. (2006). Platelet parameters in women with iron deficiency anemia. Journal of the national medical association, 98(3), 398.

11. A Study on Serum Ferritin Level In Iron Deficiency Anemia. (1980). The Korean Journal of Pathology, 14(2): 45-51.

12. Greer, J. P., Arber, D. A., Glader, B. E., List, A. F., Means, R. M., \& Rodgers, G. M. (2018). Wintrobe's clinical hematology. Lippincott Williams \& Wilkins. 